\title{
Association between bovine leukemia virus, production, and population age in Michigan dairy herds
}

\author{
R. J. Erskine ${ }^{\star}{ }^{1}$ P. C. Bartlett, ${ }^{\star}$ T. M. Byrem,† C. L. Render, ${ }^{\star}$ C. Febvay, ${ }^{\star}$ and J. T. Houseman† \\ ${ }^{*}$ Department of Large Animal Clinical Sciences, Michigan State University, East Lansing 48824 \\ †Antel BioSytems Inc., Lansing, MI 48909
}

\begin{abstract}
The objective of this study was to determine the herdlevel effect of bovine leukemia virus (BLV) infection on dairy production, culling, and cow longevity. During routine herd testing, Dairy Herd Improvement Association technicians collected milk samples from about 40 cows from each of 104 randomly selected Michigan dairy herds averaging $\geq 120$ milking cows and $11,686 \mathrm{~kg}$ of milk/yr. Milk samples were analyzed for the presence of anti-BLV antibodies by ELISA, and herd- and lactation-specific estimates of BLV prevalence were computed to determine which were the most predictive of herd milk production, culling rate, and cow longevity (proportion of cows in their third or greater lactation). On this basis, the herd BLV index (an unweighted mean BLV prevalence rate for lactation number 1, 2, 3, and $\geq 4$ ) was selected as the measure of BLV prevalence that was the most highly associated with BLV economic impact. Step-down multivariate analysis was used to determine the extent to which any of 19 herd-level management variables may have confounded the association of BLV index and measures of herd economic impact (milk production and cow longevity). The BLV index was not associated with the 12-mo culling rate, but was negatively associated in the final multivariable model with the proportion of cows that were $\geq$ third lactation, and was negatively associated with herd milk production. In summary, increased prevalence of BLV within Michigan dairy herds was found to be associated with decreased herd milk production and decreased cow longevity. Our results provide evidence that BLV infection is associated with herd-level economic impacts in high-performing dairy herds.
\end{abstract}

Key words: bovine leukemia virus, prevalence, production

Received July 23, 2011.

Accepted October 7, 2011.

${ }^{1}$ Corresponding author: erskine@cvm.msu.edu

\section{INTRODUCTION}

Enzootic bovine leukosis is a contagious disease of cattle caused by the retrovirus bovine leukemia virus (BLV). Most infected cows do not display clinical signs of disease; approximately $30 \%$ of BLV carriers will develop a persistent lymphocytosis (PL), whereas fewer than 5\% develop malignant lymphosarcoma (Schwartz and Levy, 1994). Surveys from geographic locations other than Europe have reported within-herd prevalences of BLV in adult dairy cattle from 23 to 46\% (Sargeant et al., 1997; Trono et al., 2001; Ott et al., 2003; VanLeeuwen et al., 2005). Economic losses per case of lymphosarcoma were estimated to be $\$ 412$ (Rhodes et al., 2003a). However, losses associated from subclinical forms of this disease, other than those associated with restrictions in trade or selection of animals used as genetic stock, are controversial.

The USDA National Animal Health Monitoring System (NAHMS) 1996 dairy study determined that herds with BLV test-positive cows produced $218 \mathrm{~kg}$ less milk per cow than herds that were BLV-negative (Ott et al., 2003). The mean annual value of production per cow decreased by $\$ 1.28$ for each $1 \%$ increase in herd BLV prevalence, if milk were priced at $\$ 0.29 / \mathrm{kg}$. A Canadian study of 102 herds (Sargeant et al., 1997) also determined a negative association between herd-level milk production and the presence of BLV. However, on an individual cow basis, studies have found no association between BLV serology and milk production (Jacobs et al., 1991; Kale et al., 2007; Tiwari et al., 2007), or survival in the herd (Rhodes et al., 2003b; Tiwari et al., 2005). Paradoxically, Pollari et al. (1992) reported that BLV-serologically positive cows had higher milk production than BLV-negative cows, although cows with PL were culled earlier and had lower milk production during the lactation in which they were culled. An Illinois study also reported that cows have a progressive milk loss with increasing duration of PL status (Da et al., 1993).

Currently, BLV testing results are reported to dairy producers as a dichotomous variable (negative or positive) or a numerical score, or both, based on ELISA optical density (OD). It is possible that cows with 
very high numerical scores may be less productive than are cows with scores only marginally greater than established thresholds. It is unknown if consideration of actual OD values might be more closely associated with measures of milk production and cow longevity among dairy cows that reported as BLV ELISA negative or positive only. Another objective was to determine if the associations between BLV and economic impact (milk production and cow longevity) are diminished or enhanced after adjustment for potential confounding.

\section{MATERIALS AND METHODS}

\section{Selection of Study Herds and Cows}

Dairy herds in Michigan that routinely participated in DHIA testing and averaged $\geq 120$ cows on test for the previous 12 mo were stratified into equal-sized cohorts of 119 small-sized herds (120-174 cows), 119 mediumsized herds (179-295 cows), and 119 large herds (2986,738 cows). Within each of these strata, herds were assigned a random number, which determined the order in which they were contacted and invited to participate in our study. We sought approximately 40 herds from each cohort, but exclusions because of the inability to schedule herd visits or lack of data within herd DHIA records resulted in a total of 113 participating herds. One hundred and five herds had Holstein cows only, 2 herds had Brown Swiss, 4 herds had Jerseys, and 2 herds had a mixture of breeds.

Within each herd, we identified 10 cows each from the first, second, third, and $\geq$ fourth lactations that were the most recently calved, based on the current DHIA test. On the next test day for each herd (June through August, 2010), DHIA technicians collected milk samples from the selected cows for submission to the laboratory for ELISA testing of BLV antibodies.

\section{Measures of BLV ELISA}

Milk samples were immediately preserved with 0.2 $\mathrm{mg} / \mathrm{mL}$ of bronopol and $7.8 \mu \mathrm{g} / \mathrm{mL}$ of natamycin (D \& F Control Systems Inc., Dublin, CA). Samples were first analyzed for milk components (e.g., fat, protein, and somatic cells) after transportation to a DHIA laboratory (Universal Laboratory Services, East Lansing, MI) and subsequently analyzed for antibodies to BLV as described below (Antel BioSystems Inc., East Lansing, MI). All transportation and storage of samples was at ambient temperature. All analyses for antibodies to BLV were conducted within $5 \mathrm{~d}$ of the original collection date.

Antibodies to BLV were detected using an ultrapure virus lysate in a commercially available antibody cap- ture ELISA (IDEXX Laboratories Inc., Westbrook, ME) routinely used for bulk milk analysis. Prior to analysis, individual DHIA milk samples were diluted 1:30 in sample diluent to decrease the effect of carryover contamination $(<1 \%)$ that occurs during the DHIA sampling process. Briefly, for the ELISA, antibodies to BLV in dilute milk samples bind to microtiter plate wells previously coated with virus lysate. Binding of milk antibodies is detected by reaction with horseradish peroxidase (HRP)-labeled monoclonal antibodies to bovine IgG. Attached HRP-labeled antibodies are detected by addition of enzyme substrate. Reaction times are standardized to the color development of positive controls $(0.9<450 \mathrm{~nm}$ OD $<1.2)$ and stopped by the addition of $\mathrm{H}_{2} \mathrm{SO}_{4}$. Mean sample scores of the duplicate samples (sample OD - negative control OD) $\geq 0.1$ were considered positive.

For each herd, a BLV index was calculated as the unweighted average of the BLV prevalence for the 4 lactation groups $(1,2,3$, and $\geq 4)$, and was thus independent of the herd's age distribution. The correlation between the BLV index and actual herd prevalence (as measured by testing all lactating cows within a herd) was determined to be 0.994 (R. J. Erskine, unpublished data).

\section{Herd Production and Survey Data}

Within 2 wk either before or after the date of milk collection, study investigators visited each farm to conduct a survey of farm management practices, housing, and environment. The 12-mo rolling herd averages, retroactive from and including the test date that milk samples were collected for BLV ELISA, were determined for milk production (RHA), SCC, number of cows on test, and DIM. Herd removal rate (CULL) was the number of cows reported as culled or died, divided by the 12-mo average number of cows in the herd. The percentage change in cows in the herd over the 12-mo period before the BLV ELISA test date (PCTCHG) was calculated as the quotient of the number of cows on test on the day that milk samples were collected, divided by the number of cows on test on the test date 12 mo before sample collection, multiplied by 100 . Projected minimum calving interval was used from the DHIA report calculated from the sample collection test date. The proportion of cows in the herd of third or greater lactation (PROP3) was determined for the day of milk sample collection.

Because of breed-related variation in production, the 8 herds that included breeds other than Holsteins were excluded from RHA analysis. Additionally, 1 herd lacked sufficient records to determine SCC and calving interval. As such, 112 herds were available for 
the analysis of CULL and PROP3, but only 104 allHolstein herds were available for the analysis of RHA. Because of marketing-related regulations, dairy herds in the entire state of Michigan had been excluded from the use of bST throughout the 12-mo period before herd visits, and thus, use of this technology did not affect our analysis.

\section{Herd Measures of BLV Prevalence}

We calculated 26 different measures of herd-level BLV infection to determine which ones were the most strongly associated with RHA, CULL, and PROP3. Prevalence measures always considered ELISA scores $>0.1$ OD as positive. Milk OD scores were summarized for the entire herd as well as for specific lactations. BLV prevalence estimates involving cows from all lactations included the BLV index (described above) and herd prevalence (HRDPREV), which was an average of the 4 lactation-specific prevalence rates (LACT) weighted according to each herd's actual age distribution. Because the distribution of OD scores were strongly skewed to the right (skewness $=1.8$, Kolmogorov-Smirnov D normality $=0.28)$, we also evaluated the mean and median of a log transformation of the cow-specific OD data.

Each of the 26 measures of BLV ELISA was independently evaluated as the sole predictor of CULL, RHA, and of PROP3, using simple linear regression, to determine which measure of BLV ELISA was the most predictive. To determine if significant associations could have been largely due to confounding, step-down multivariable models were developed for BLV index (the most predictive BLV measure that included cattle from all lactations) to adjust for any potential confounding due to 19 herd-level management variables. Variable selection ceased when all variables were significant at $P<0.05$ by type III sum of squares. Two-way interactions and quadratic terms were evaluated, and the Shapiro-Wilk W normal of the residuals was used to confirm the validity of the general linear model's statistical assumptions.

Categorical variables recorded from the survey included exclusive use of freestall housing in adult cattle; use of AI (exclusively, partially, or none) for adult cows or heifers; separation of first-lactation animals from older cows; separation of close-up dry cows from other herd mates; separation of postparturient (transition) cows from other herd mates; frequency of milking per day; purchase of replacements within 1, 2, or $3 \mathrm{yr}$; whether the herd was closed or open, bulls included; and if needles were routinely changed before each injection. Continuous variables included SCC, DIM, calving interval, number of cows on test, and PCTCHG from DHIA records. From the survey, variables included the number of diagnoses used to confirm pregnancy for adults and heifers and the number of routine injections (sum of reproductive, immunization, and preventive injections) that were administered to adult cows each year.

\section{RESULTS}

The 12-mo rolling mean $( \pm \mathrm{SEM})$ number of cows on test was $425 \pm 72.5$, and the average increase in herd size during the 12 -mo period was $3.9 \pm 0.7 \%$ (Table 1 ); only 2 herds reported an increase in herd size by more than $20 \%$. At the time of selection for participation in the trial, all herds reported $\geq 120$ cows on test. However, because of a 3-mo time period that was required to complete all of the enrollments (survey and collection of milk samples for BLV ELISA) subsequent to herd selection, 1 herd had an actual 12-mo rolling average of 116 cows on the day of enrollment; this herd was kept in the trial. The mean RHA was $11,686 \pm 113 \mathrm{~kg}$ of milk/cow per year (Table 1 ). The mean 12-mo SCC was $182,300 \pm 6.6$ cells $/ \mathrm{mL}$; all trial herds reported a $12-\mathrm{mo}$ SCC of $<400,000$ cells/mL. Mean 12-mo DIM was 183 $\pm 1.4 \mathrm{~d}$, and the mean minimum calving interval was $13.7 \pm 0.1 \mathrm{mo}$.

\section{Simple Linear Regression: CULL, RHA, and PROP3}

The 12-mo CULL was not associated with BLV index, HRDPREV, any of the LACT, or any of the OD variables $(P>0.47$ in all instances; residuals always normally distributed at $P>0.98)$. On simple linear regression, BLV index never contributed at $P<0.5$ to the step-down model to predict CULL with the 19 potential confounding variables; the residuals were always normally distributed with a Shapiro-Wilk normality statistic $>0.9$.

For each of our 26 herd-level measures of BLV ELISA, the results of simple linear regression models to predict RHA and PROP3 were determined (Table 2). The BLV prevalence rate for cattle in their third lactation (LACT3) was the measure of herd BLV ELISA, which was most strongly associated with both herd RHA and PROP3. For each of the first 3 lactation cohorts, the LACT (LACT1, LACT2, and LACT3) were more significantly associated with both RHA and PROP3 than were any of the untransformed or log-transformed measures of ELISA OD score, indicating that no added predictive benefit could be obtained by using actual OD scores rather than a simple prevalence measure of the percentage of cattle in the herd that were positive at OD score $>0.1$ (Table 2). However, the mean of the OD score for the $\geq 4$ lactation cattle and the mean of the log-transformed OD score for the $\geq 4$ lactation cattle 
Table 1. Descriptive data from 104 Michigan Holstein dairy herds that participated in DHIA testing

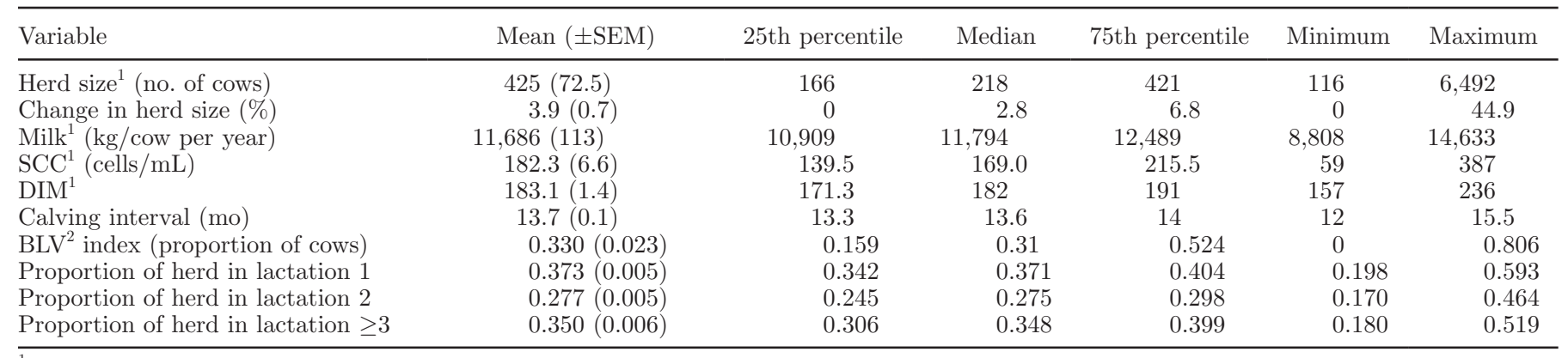

${ }^{1}$ Twelve-month rolling average.

${ }^{2} \mathrm{BLV}=$ bovine leukemia virus.

were both more significantly associated with PROP3 ( $P=0.0041$ and $P=0.0042$, respectively) than was the corresponding simple prevalence rate (LACT4). In all other instances, the measures of simple percent ELISA positive (BLV index, HRDPREV, LACT1, LACT2, LACT3, and LACT4) were more predictive of both PROP3 and RHA than were the corresponding measures based on the actual OD score. Based on the above data (Table 2), BLV index was selected as the measure of BLV prevalence for regression analysis because it was more highly associated with both RHA and PROP3 than any other measure of BLV prevalence that included all of the lactation groups.

The simple linear regression model of RHA indicated that BLV index was a significant continuous-level independent variable $(P=0.0166)$. The coefficient of determination was 0.0544 and the residuals were distributed normally $(\mathrm{W}=0.99)$. The regression coefficient of $-1,151(\mathrm{SE}=473)$ suggested that each 0.1 increase in the proportion of positive cattle was associated with a 115-kg decrease in RHA (Figure 1).

The simple linear regression model of PROP3 indicated that BLV index was a significant continuous-level independent variable $(P=0.0021)$. The coefficient of determination was 0.0817 and the residuals were distributed normally $(\mathrm{W}=0.99)$. The regression coefficient of $-0.0755(\mathrm{SE}=0.0240)$ suggested that each 0.1 increase in the proportion of positive BLV cattle was associated with a 0.00755 decrease in the proportion of cattle $\geq 3$ lactations (Figure 2).

\section{Evaluation of Possible Confounding}

The final multivariable model to predict RHA is shown in Table 3. No 2-way interactions or quadratic terms were significant. Higher SCC was associated with decreased milk production. Milking cows twice per day, instead of 3 or more times per day, was associated with lower milk production. The multivariable regression coefficient for BLV index indicated that every 0.1 increase in the proportion of cattle positive for BLV was associated with a decrease of $140 \mathrm{~kg}$ of milk production.

The final multivariable model to predict PROP3 is shown in Table 4. No quadratic terms were significant, but a significant interaction was found between BLV index and the average number of pregnancy checks for heifers (i.e., the number of palpations used to diagnose and confirm pregnancy in primiparous heifers, H_PRG_PL). With the interaction term removed, the negative regression term for BLV index indicated that every 0.1 increase in the proportion of cattle positive for BLV was associated with a decrease of 0.00847 in PROP3.

\section{DISCUSSION}

Both a Canadian (Sargeant et al., 1997) and the NAHMS (Ott et al., 2003) study reported a negative association between herd-level milk production and the presence of BLV. Additionally, the NAHMS study determined that annual value of production per cow linearly decreased in association with each incremental increase in herd BLV prevalence. Our study was in close agreement with the NAHMS study; we also found a negative linear correlation between herd BLV prevalence and herd milk production. Furthermore, quadratic terms in our models were not significant, indicating that a decidedly linear relationship existed between BLV index and PROP3 and between BLV index and RHA. Our finding of linear relationships is consistent with the hypothesis that BLV infection could be causally related to decreased cow longevity and milk production. For example, each $10 \%$ increase in herdlevel BLV prevalence is associated with the exact same effect on milk production and cow longevity.

When we attempted to adjust for the 19 variables that might be associated with production and longevity, the effect of BLV index on PROP3 and RHA was 


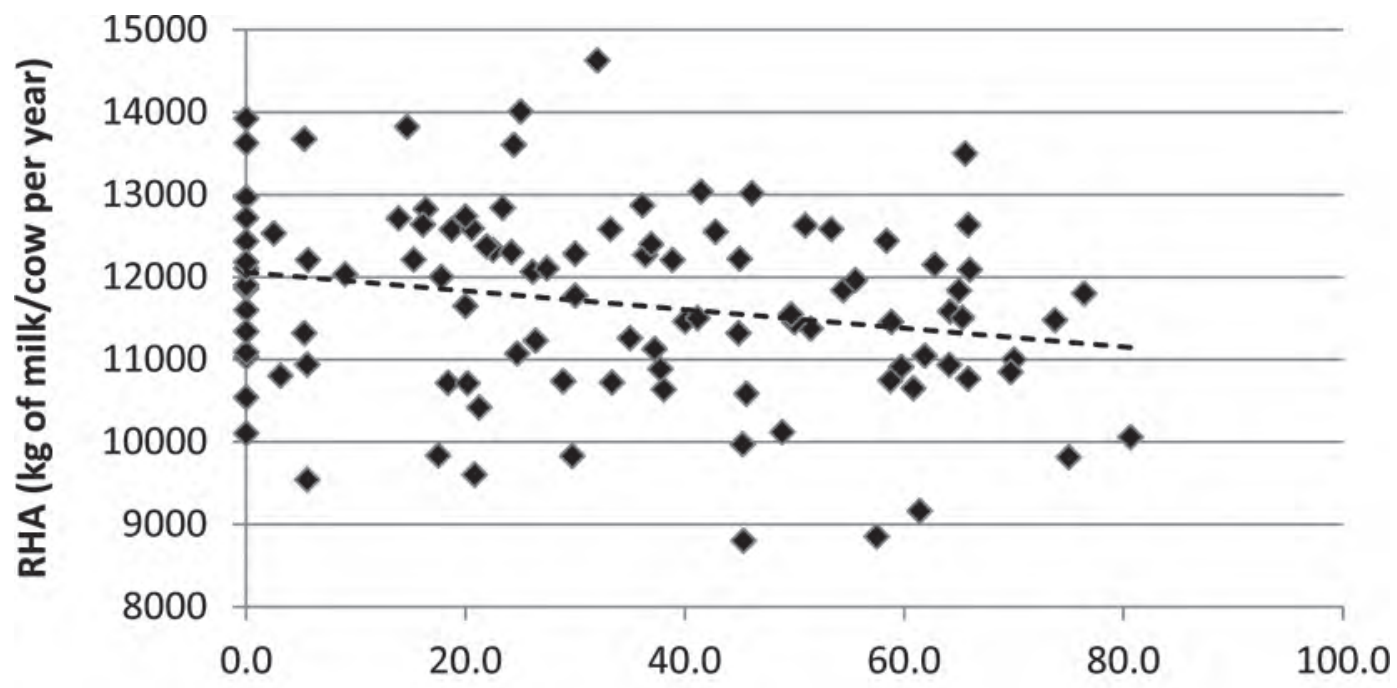

\section{BLV Index (\% of cows in herd)}

Figure 1. Scattergram of 12-mo rolling herd average milk yield (RHA) by herd prevalence of bovine leukemia virus, as measured by an ageindependent index (BLV index), for 104 Michigan dairy farms that participated in DHIA $(\mathrm{r}=0.233 ; P=0.0166)$.

Table 2. Coefficient of determination $\left(\mathrm{R}^{2}\right)$ and $P$-value for associations between measures of herd-level prevalence of bovine leukemia virus (BLV) in lactating, adult dairy cows and within-herd proportion of cows with $\geq 3$ lactations (PROP3; $\mathrm{n}=112$ herds) and rolling 12-mo herd average milk yield (RHA; $\mathrm{n}=104$ herds)

\begin{tabular}{|c|c|c|c|c|}
\hline \multirow[b]{2}{*}{ BLV prevalence ${ }^{1}$} & \multicolumn{2}{|c|}{ PROP3 } & \multicolumn{2}{|c|}{ RHA } \\
\hline & $\mathrm{R}^{2}$ & $P$-value & $\mathrm{R}^{2}$ & $P$-value \\
\hline LACT1 & 0.0470 & 0.0211 & 0.0254 & 0.1041 \\
\hline LACT2 & 0.0446 & 0.0247 & 0.0485 & 0.0239 \\
\hline LACT3 & 0.0963 & 0.0008 & 0.0602 & 0.0117 \\
\hline LACT4 & 0.0490 & 0.0184 & 0.0247 & 0.1094 \\
\hline HRDPREV & 0.0564 & 0.0113 & 0.0544 & 0.0167 \\
\hline BLV index & 0.0817 & 0.0021 & 0.0544 & 0.0166 \\
\hline $\mathrm{AOD}$ & 0.0670 & 0.0066 & 0.0322 & 0.0712 \\
\hline MOD & 0.0280 & 0.0819 & 0.0249 & 0.1131 \\
\hline ALOD & 0.0676 & 0.0063 & 0.0325 & 0.0699 \\
\hline MLOD & 0.0284 & 0.0796 & 0.0255 & 0.1085 \\
\hline AOD1 & 0.0297 & 0.0733 & 0.0054 & 0.4636 \\
\hline MOD1 & 0.0349 & 0.0518 & 0.0077 & 0.3809 \\
\hline ALOD1 & 0.0307 & 0.0684 & 0.0061 & 0.4338 \\
\hline MLOD1 & 0.0355 & 0.0497 & 0.0087 & 0.3523 \\
\hline AOD2 & 0.0443 & 0.0280 & 0.0220 & 0.1366 \\
\hline MOD2 & 0.0210 & 0.1326 & 0.0142 & 0.2335 \\
\hline ALOD2 & 0.0442 & 0.0281 & 0.0225 & 0.1323 \\
\hline MLOD2 & 0.0211 & 0.1318 & 0.0145 & 0.2283 \\
\hline AOD3 & 0.0458 & 0.0254 & 0.0297 & 0.0833 \\
\hline MOD3 & 0.0281 & 0.0815 & 0.0260 & 0.1053 \\
\hline ALOD3 & 0.0485 & 0.0214 & 0.0307 & 0.0783 \\
\hline MLOD3 & 0.0309 & 0.0676 & 0.0268 & 0.1005 \\
\hline AOD4 & 0.0743 & 0.0041 & 0.0318 & 0.0730 \\
\hline MOD4 & 0.0455 & 0.0260 & 0.0198 & 0.1585 \\
\hline ALOD4 & 0.0742 & 0.0042 & 0.0311 & 0.0763 \\
\hline MLOD4 & 0.0457 & 0.0256 & 0.0206 & 0.1500 \\
\hline
\end{tabular}

${ }^{1} \mathrm{LACT} 1-\mathrm{LACT} 4$ = within-herd proportion of cows positive for BLV by lactation; HRDPREV $=$ BLV herd prevalence, weighted for proportion of herd by lactation $(1$ through $\geq 4)$; BLV index $=$ unweighted (for proportion of herd by lactation) mean herd BLV prevalence; AOD = mean herd BLV optical density (OD; entire herd and lactations 1-4); MOD = median herd BLV OD (entire herd and lactations 1-4); ALOD = mean log of the BLV OD (entire herd and lactations 1-4); MLOD = median log of the BLV OD (entire herd and lactations $1-4)$. 
Table 3. Final model for associations between herd bovine leukemia virus (BLV) index and herd-level variables on rolling 12-mo herd average milk yield in 104 Michigan Holstein dairies ${ }^{1}$

\begin{tabular}{lccr}
\hline Parameter $^{2}$ & Estimate & SE & $P$-value \\
\hline Intercept & 13,648 & 299 & $<0.0001$ \\
BLV index & $-1,397$ & 402 & 0.0008 \\
Milking twice per day & $-1,049$ & 186 & $<0.0001$ \\
SCC & -5.38 & 1.36 & 0.0001 \\
\hline
\end{tabular}

${ }^{1} \mathrm{R}^{2}=0.375$; residuals are normally distributed (Shapiro-Wilk $\mathrm{W}=$ $0.99) ; \mathrm{n}=104$ herds.

${ }^{2} \mathrm{BLV}$ index $=$ unweighted (for proportion of herd by lactation) mean herd BLV prevalence; $\mathrm{SCC}=12$-mo rolling herd average SCC.

stronger than simple linear regression. Thus, the confounders were partially masking the strength of the association between BLV index and RHA and BLV index and PROP3.

Maintaining lower SCC and higher frequency of milking have been well established as positive influences on herd-level production. Although other generally accepted management practices, such as use of AI breeding and more frequent palpation to determine heifer pregnancy (H_PRG_PL) were positively associated with RHA in our analysis, these variables did not remain in the final model at the $95 \%$ significance level. More frequent diagnosis of heifer pregnancy (H_PRG_PL) was the only 1 of the 19 potential confounders that remained in the final model between BLV index and PROP3. Despite the paucity of variables included in our final models, the coefficient of determination was a surprisingly robust 0.37 and 0.21 for the RHA and PROP3 models, respectively.
Table 4. Final model for associations between herd bovine leukemia virus (BLV) index and herd-level variables on the proportion of cows $\geq$ lactation 3 in 112 Michigan Holstein dairies ${ }^{1}$

\begin{tabular}{lccr}
\hline Parameter $^{2}$ & Estimate & SE & $P$-value \\
\hline Intercept & 0.386 & 0.0148 & $<0.0001$ \\
BLV index & -0.175 & 0.0386 & $<0.0001$ \\
H_PRG_PL & -0.0150 & 0.0146 & 0.3073 \\
BLV index $\times$ H_PRG_PL & 0.1023 & 0.0351 & 0.0043
\end{tabular}

${ }^{1} \mathrm{R}^{2}=0.202$; residuals are normally distributed (Shapiro-Wilk $\mathrm{W}=$ $0.99) ; \mathrm{n}=112$ herds.

${ }^{2} \mathrm{BLV}$ index = unweighted (for proportion of herd by lactation) mean herd BLV prevalence; H_PRG_PL = number of palpations used to diagnose and confirm pregnancy in primiparous heifers.

The purpose of this study was to better understand the association of BLV antibody prevalence with dairy herd-level milk production and cow longevity. On an individual cow basis, some studies have found no association between BLV serology and milk production (Jacobs et al., 1991; Kale et al., 2007; Tiwari et al., 2007) or survival in the herd (Rhodes et al., 2003b; Tiwari et al., 2005). Paradoxically, one report found that BLV-serologically positive cows had higher milk production than BLV-negative cows (Pollari et al., 1992), and also determined that BLV serology was not indicative of decreased milk production or culling. However, in our study, as in the majority of herd and cow-level BLV studies, the extent or duration of infection was not documented. In the Pollari et al. (1992) study, persistently lymphocytotic cows were culled earlier and had lower milk production during the lactation they were culled. An Illinois study also reported that cows have

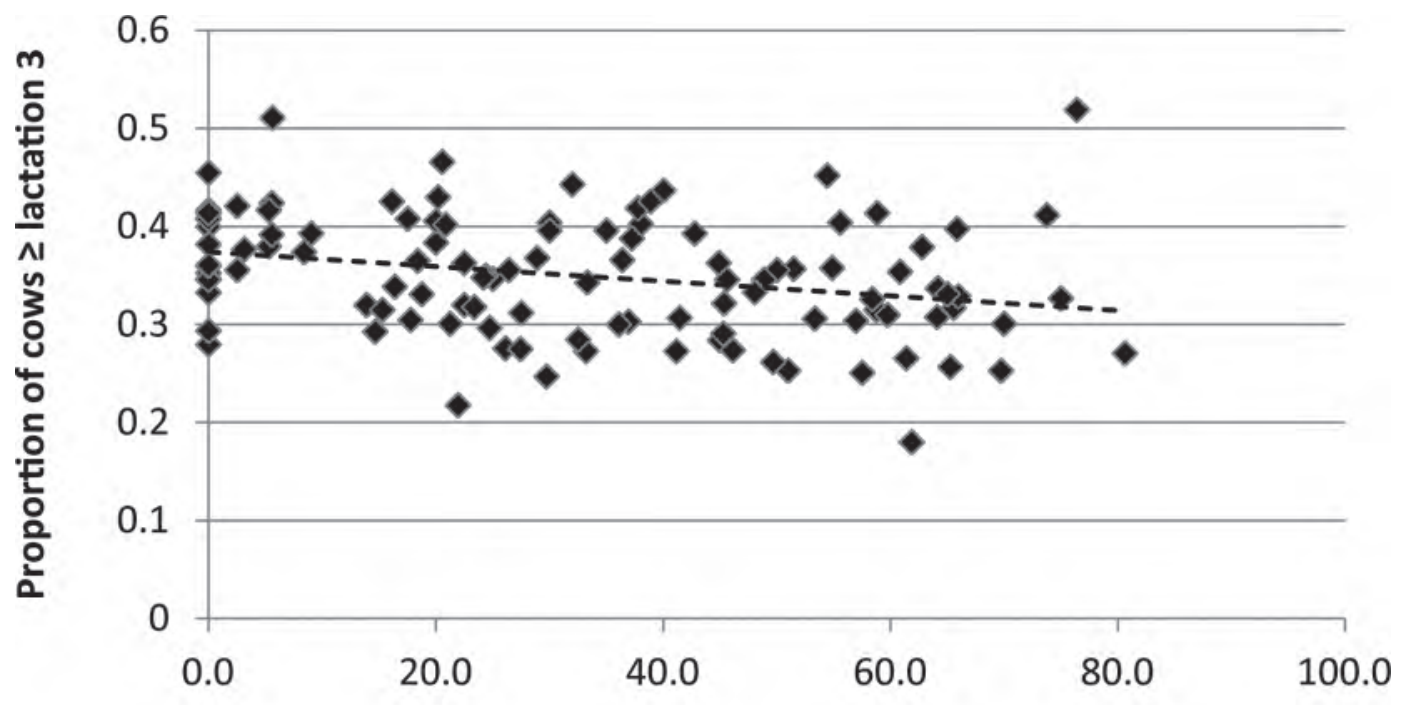

\section{BLV Index (\% of cows in herd)}

Figure 2. Scattergram of the proportion of cows in a herd of $\geq$ third lactation (PROP3) by herd prevalence of bovine leukemia virus, as measured by an age-independent index (BLV index), for 104 Michigan dairy farms that participated in DHIA $(\mathrm{r}=0.286 ; P=0.0021)$ 
progressive milk loss with increasing duration of $\mathrm{PL}$ (Da et al., 1993).

The cow removal rate (combination of cows that died and culled cows) was not associated with BLV prevalence. This agrees with previous reports that BLV seroprevalence was not associated with cow survival (Rhodes et al., 2003b; Tiwari et al., 2005). However, we question if overall cow removal rate is the appropriate measure of the effect that BLV, or any disease, may have on herd-level survival. Proportions of specific diagnoses of cow removal and associated risk factors are likely a better indicator of understanding the dynamics of removal rates within dairy herds. A Pennsylvania study of over 2,000 dairies determined that early lactation $(<60$ DIM) and increasing lactation number was associated with increasing risk of culling (Dechow and Goodling, 2008), but many herds had low early-lactation CULL and had similar overall CULL, which varied widely. Although better managed herds may be able to choose cows for removal based on economic reasons (Fetrow et al., 2006), as opposed to involuntary causes, unless herds are suffering catastrophic mortality, or attempting to expand substantially, the total CULL of voluntary and culled/died removals is not likely to change, whether from the presence of a disease or limitations in available housing.

Only 2 of our trial herds increased in size by $>20 \%$ in the previous 12 mo. Consistent herd size among the herds in our study during the summer of 2010 was predictable; the dairy industry was recovering from unprofitable milk prices in the previous year. Thus, the lack of change in size among herds in our study supports our finding that the proportion of older cows in the herd may have been a better indicator of the association of BLV with longevity than overall CULL.

The ambiguous nature of the association between BLV, longevity, and milk production may, in part, result from difficulty in establishing the existence of a diseased state in BLV-infected cows. The disease progresses slowly; many cows are culled from herds for a variety of causes, often at an age that precludes the possible development of lymphocytosis or lymphosarcoma; and a large proportion of infections remain asymptomatic. Additionally, numerous within-herd and between-herd determinants exist that can affect both milk yield and longevity. Part of the disparity between the BLV associations with herd-level, as compared with cow-level, milk production may be accounted for by the limited number of herds that were included in the cow-level studies. Variation occurred between studies in sampling regimens, and in the case of our study, the use of milk versus serum for antibody detection. Measures of milk production have varied considerably between studies, and have often recorded only current lactation data, such as 305-d milk, from the time point of sampling for BLV testing. Reports have indicated diversity among BLV viral strains, and this may contribute to the existence of persistently BLV-infected animals that are PCR positive, but seronegative (Fechner et al., 1997; Monti et al., 2005; Rodriguez et al., 2009). However, residual confounding from extraneous variables (not in our models) might have occurred, and additionally, our survey could not discriminate for the inevitable variation in compliance of reported management practices, especially on farms with larger labor forces.

The population of herds selected for this study was prescribed to facilitate sampling of milk on DHIA testing dates, implying participation in DHIA testing and, thus, an enhanced level of management that included regular monitoring and use of records. The mean milk production of $11,686 \mathrm{~kg} / \mathrm{cow}$ per year of the trial herds was well above the national average of $9,613 \mathrm{~kg} / \mathrm{cow}$ per year and the Michigan average of $10,573 \mathrm{~kg} / \mathrm{cow}$ per year (USDA, 2010). Wu et al. (1989) reported that BLV-infected cows with high genetic potentials for milk and fat yields were more susceptible to developing PL than lower genetic potential cows, and cows with PL do not produce milk or fat according to predicted genetic values. Additionally, a major histocompatibility complex class I (BoLA-A) allele that is associated with resistance to $\mathrm{PL}$ is also associated with increased milk production potential and longevity (Da et al., 1993). The relationship between milk production, genetics, and resistance to BLV is complex, but this raises an intriguing theory that part of the disparity between our study and previous studies may be accounted for by a population of herds that were genetically superior for milk production, and concurrent genetic association with susceptibility to BLV.

\section{CONCLUSIONS}

The BLV index, defined as the unweighted average of the BLV prevalence rates for the first, second, third and $\geq$ fourth lactation, was more strongly associated with both PROP3 and RHA than was any other whole-herd measure of BLV antibodies. Herd-level BLV prevalence was negatively associated with both RHA milk and PROP3. These negative relationships were decidedly linear, and adjustment for significant confounders increased the magnitude of the effect measures (regression coefficients) and the statistical significance of the observed associations. Our findings are consistent with the hypothesis that subclinical BLV infection may be associated with decreased dairy productivity and profitability. 


\section{ACKNOWLEDGMENTS}

The authors gratefully acknowledge funding of this project by the Elwood Kirkpatrick Dairy Science Research Endowment, IDEXX Laboratories (Westbrook, $\mathrm{ME}$ ), and technical support by Antel BioSystems Inc. (Lansing, MI).

\section{REFERENCES}

Da, Y., R. D. Shanks, J. A. Stewart, and H. A. Lewin. 1993. Milk and fat yields decline in bovine leukemia virus-infected Holstein cattle with persistent lymphocytosis. Proc. Natl. Acad. Sci. USA 90:6538-6541.

Dechow, C. D., and R. C. Goodling. 2008. Mortality, culling by sixty days in milk, and production profiles in high- and low-survival Pennsylvania herds. J. Dairy Sci. 91:4630-4639.

Fechner, H., P. Blankenstein, A. Looman, J. Elwert, L. Geue, C. Albrecht, A. Kurg, D. Beier, O. Marquardt, and D. Ebner. 1997. Provirus variants of the bovine leukemia virus and their relation to the serological status of naturally infected cattle. Virology 237:261-269.

Fetrow, J., K. V. Nordlund, and H. D. Norman. 2006. Invited review: Culling: Nomenclature, definitions, and recommendations. J. Dairy Sci. 89:1896-1905.

Jacobs, R. M., J. L. Heeney, M. A. Godkin, K. E. Leslie, J. A. Taylor, C. Davies, and V. E. O. Valli. 1991. Production and related variables in bovine leukaemia virus-infected cows. Vet. Res. Commun. $15: 463-474$.

Kale, M., O. Bulut, O. Yapkic, M. S. Gulay, F. Pehlivanoglu, A. Ata, and S. Yavru. 2007. Effects of subclinical bovine leukemia virus infection on some production parameters in a dairy farm in southern Turkey. J. S. Afr. Vet. Assoc. 78:130-132.

Monti, G., R. Schrijver, and D. Beier. 2005. Genetic diversity and spread of bovine leukaemia virus isolates in Argentine dairy cattle. Arch. Virol. 150:443-458.

Ott, S. L., R. Johnson, and S. J. Wells. 2003. Association between bovine-leukosis virus seroprevalence and herd-level productivity on U.S. dairy farms. Prev. Vet. Med. 61:249-262.

Pollari, F. L., V. L. Wangsuphachart, R. F. DiGiacomo, and J. F. Evermann. 1992. Effects of bovine leukemia virus infection on production and reproduction in dairy cattle. Can. J. Vet. Res. 56:289-295.
Rhodes, J. K., K. D. Pelzer, and Y. J. Johnson. 2003a. Economic implications of bovine leukemia virus infection in mid-Atlantic dairy herds. J. Am. Vet. Med. Assoc. 223:346-352.

Rhodes, J. K., K. D. Pelzer, Y. J. Johnson, and E. Russek-Cohen. 2003b. Comparison of culling rates among dairy cows grouped on the basis of serologic status for bovine leukemia virus. J. Am. Vet. Med. Assoc. 223:229-231.

Rodriguez, S. M., M. D. Golemba, R. H. Campos, K. Trono, and L. R. Jones. 2009. Bovine leukemia virus can be classified into seven genotypes: Evidence for the existence of novel clades. J. Gen. Virol. 90:2788-2797.

Sargeant, J. M., D. F. Kelton, S. W. Martin, and E. D. Mann. 1997. Associations between farm management practices, productivity, and bovine leukemia virus infection in Ontario dairy herds. Prev. Vet. Med. 31:211-221.

Schwartz, I., and D. Levy. 1994. Pathobiology of bovine leukemia virus. Vet. Res. 25:521-536.

Tiwari, A., J. A. VanLeeuwen, I. R. Dohoo, G. P. Keefe, J. P. Haddad, and R. Tremblay. 2007. Production effects of pathogens causing bovine leukosis, bovine viral diarrhea, paratuberculosis, and neosporosis. J. Dairy Sci. 90:659-669.

Tiwari, A., J. A. VanLeeuwen, I. R. Dohoo, H. Stryhn, G. P. Keefe, and J. P. Haddad. 2005. Effects of seropositivity for bovine leukemia virus, bovine viral diarrhoea virus, Mycobacterium avium subspecies paratuberculosis, and Neospora caninum on culling in dairy cattle in four Canadian provinces. Vet. Microbiol. 109:147-158.

Trono, K. G., D. M. Pérez-Filgueira, S. Duffy, M. V. Borca, and C. Carrillo. 2001. Seroprevalence of bovine leukemia virus in dairy cattle in Argentina: Comparison of sensitivity and specificity of different detection methods. Vet. Microbiol. 83:235-248.

USDA. 2010. National Agricultural Statistics Service, Quick Stats. Accessed June 29, 2011. http://quickstats.nass.usda.gov/ results/6503AAF4-BE1B-3D80-AFD2-9BADE1DAAB11 and http://quickstats.nass.usda.gov/results/9D0270C9-2982-3F3C8486-F2AEFF9F5962.

VanLeeuwen, J. A., L. Forsythe, A. T. Tiwari, and R. Chartier. 2005. Seroprevalence of antibodies against bovine leukemia virus, bovine viral diarrhea virus, Mycobacterium avium subspecies paratuberculosis, and Neospora caninum in dairy cattle in Saskatchewan. Can. Vet. J. 46:56-58.

Wu, M. C., R. D. Shanks, and H. A. Lewin. 1989. Milk and fat production in dairy cattle influenced by advanced subclinical bovine leukemia virus infection. Proc. Natl. Acad. Sci. USA 86:993-996. 